\title{
Special Issue: Nervous System and Exercise
}

\section{Guest Editors}

Phil Gardiner

Spinal Cord Research Center Rady Faculty of Health Sciences

University of Manitoba

Winnipeg, Manitoba, Canada

Vladimir Ljubicic

Department of Kinesiology

McMaster University

Hamilton, Ontario, Canada

\section{Sponsor}

Canadian Society for Exercise Physiology

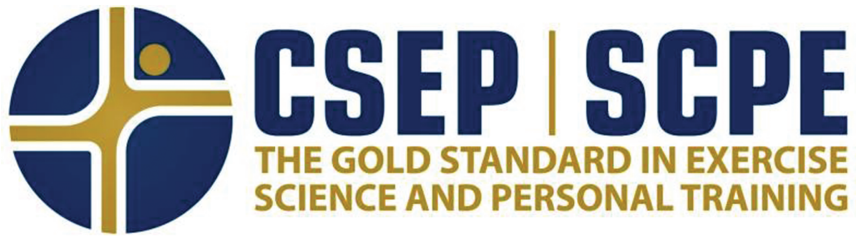

